\title{
Study of the clinical and functional characteristics of asthmatic children with obstructive sleep apnea
}

\author{
This article was published in the following Dove Press journal: \\ Journal of Asthma and Allergy \\ 12 October 2017 \\ Number of times this article has been viewed
}

\author{
Yen Nguyen-Hoang \\ Thuy Nguyen-Thi-Dieu ${ }^{2}$ \\ Sy Duong-Quy ${ }^{3-5}$ \\ 'Department of Pediatrics, Phu Tho \\ General Hospital, Phu Tho Province, \\ ${ }^{2}$ Department of Pediatrics, Hanoi \\ Medical University, Hanoi, ${ }^{3}$ Biomedical \\ Research Center, Lam Dong Medical \\ College, Dalat, Vietnam; ${ }^{4}$ Department \\ of Physiology and Lung Function \\ Testing, Cochin Hospital, Paris \\ Descartes University, Paris, France; \\ ${ }^{5}$ Division of Asthma and Immuno- \\ Allergology, Hershey Medical Center, \\ Penn State Medical College, Hershey, \\ PA, USA
}

Correspondence: Sy Duong-Quy Biomedical Research Center, Lam Dong Medical College, 16 Ngo Quyen, Dalat, Vietnam

Fax +8463 38I 5000

Email sduongquy.jfvp@gmail.com
Background and objective: The obstructive sleep apnea (OSA) is a common respiratory disorder in children, especially those at preschool and school ages. This study aimed to describe the characteristics of asthmatic children with OSA and the symptoms for a high risk of OSA. Subjects and methods: It was a prospective and descriptive study. The data of asthmatic children including medical history, clinical examination, blood tests, spirometry, exhaled nitric oxide (NO), and respiratory polygraphy were registered for analyses.

Results: Eighty-five asthmatic children with a mean age of $9.5 \pm 2.1$ years were included. The prevalence of OSA was $65.9 \%(56 / 85)$ in study subjects. The prevalence of severe OSA in children with moderate asthma was significantly higher than intermittent and mild asthma. The percentage of asthmatic children with OSA who had snoring, sleep disturbance, and nocturnal sweats was significantly higher than that of asthmatic children without OSA ( $48.2 \%$ vs $17.2 \%$, $71.4 \%$ vs $27.5 \%$, and $55.1 \%$ vs $31.0 \%$, respectively). The presence of allergic rhinitis and snoring was associated significantly with a high probability for the presence of OSA.

Conclusion: Children with asthma have a risk of OSA. Asthmatic children with suggested symptoms such as snoring or waking up at night should be screened for OSA.

Keywords: asthma, OSA, snoring, allergic rhinitis

\section{Introduction}

Obstructive sleep apnea (OSA) is characterized by repetitive and partial or total collapse of the upper airway during sleep. This disorder results in decreased or complete cessation of airflow during sleep despite the presence of breathing effort. ${ }^{1}$ OSA is the most common respiratory disorder during sleep and has a significant prevalence in the general population. ${ }^{2}$ In children, the prevalence of OSA is approximately $1.2 \%-5.7 \%$, with the high peak in preschool and school-aged children. ${ }^{3,4}$ Recently, an increasing number of studies have been conducted to study the relationship between OSA and other lower airway diseases especially in asthma in terms of prevalence, pathophysiology, and disease control. Previous studies suggested that asthma and OSA may coexist because they are chronic inflammations of the airways. ${ }^{5,6}$ However, until now, the prevalence of OSA in patients with asthma, especially in children with asthma, has not been clearly demonstrated. In a recent systematic review, Sánchez et al ${ }^{7}$ showed that children with asthma had a significant and higher risk of OSA than subjects without OSA and that both diseases shared some similar symptoms (overlap) during sleep, making the diagnosis of each more difficult.

In children with OSA, due to the intermittent hypoxia at night, in the long term they might develop hemodynamic, metabolic, and mental disorders. These consequences 
are more hazardous with harmful effects on the psychological and physical development and also on the ability of learning and memory performance in children with OSA. ${ }^{8,9}$ In asthmatic children with OSA, these symptoms were more severe and usually associated with sleep disturbance, daytime sleepiness, and tiredness. ${ }^{10}$ Furthermore, OSA is also a common comorbidity in asthma and may disturb asthma control, and inversely, the asthma status makes OSA more severe. ${ }^{11}$

This study was planned to describe: 1) the prevalence of OSA in children with asthma; 2) the clinical and functional characteristics of asthmatic children with OSA; and 3) the suggestive symptoms of asthmatic children for a higher risk of OSA.

\section{Subjects and methods Subjects}

Children diagnosed with asthma who had been presented to the Department of Asthma and Immuno-Allergology of the National Hospital of Pediatrics (Hanoi, Vietnam) from November 2015 to August 2016 were included in the present study after their parents or legal guardians signed an institutional review board-approved consent form.

\section{Inclusion criteria}

All subjects diagnosed with asthma and aged between 6 and 17 years were included in the present study if they were out of acute asthma exacerbation and able to perform spirometry, exhaled nitric oxide (NO) measurement, skin prick test (SPT), and polygraphy (PG) at night. The diagnosis of asthma was based on the criteria recommended by Global Initiative for Asthma (GINA) 2015 for children over 5 years old. ${ }^{12}$ The subjects who had other diseases had been excluded from the present study.

\section{Exclusion criteria}

Study subjects were excluded from the study if they had one of the following features: asthma crisis or severe asthma exacerbations needing systemic corticosteroid therapy (oral or injection) at inclusion, any significant other chronic or acute diseases, facial structure malformation, or enlarged tonsils.

\section{Methods}

\section{Study design}

It was a prospective and descriptive study. All study subjects were followed up regularly at the Department of Asthma and Immuno-Allergology. This study was approved by the ethical review board of the National Hospital of Pediatrics (Hanoi, Vietnam).
Depending on asthma severity, the study subjects were treated as recommended by GINA (intermittent asthma: shortacting beta agonist [SABA] as needed; mild asthma: low-dose inhaled corticosteroid (ICS) + SABA; moderate asthma: moderate- to high-dose ICS + SABA; severe asthma: moderate- to high-dose ICS + long-acting beta agonist + SABA). The asthma control test (ACT) was used as a self-assessment by the study subjects ( $\geq 12$ years) or their parents ( $<12$ years). The level of asthma control was defined as recommended by GINA: controlled, partially controlled, and uncontrolled asthma. ${ }^{12}$

OSA was diagnosed by PG, and the apnea-hypopnea index (AHI) was used to classify the severity of OSA for children $\leq 12$ years as recommended: normal (non-OSA): AHI $\leq 1 / \mathrm{h}$; mild OSA: $1 / \mathrm{h}<\mathrm{AHI} \leq 5 / \mathrm{h}$; moderate OSA: $5 / \mathrm{h}$ $<\mathrm{AHI} \leq 10 / \mathrm{h}$; and severe OSA: AHI $>10 / \mathrm{h} .{ }^{13}$ The severity of OSA for children $>12$ years was defined similarly with adult classification: normal (non-OSA): AHI $\leq 5 / \mathrm{h}$; mild OSA: 5/h $<$ AHI $\leq 15 / h$; moderate OSA: $15 / \mathrm{h}<\mathrm{AHI} \leq 30 / \mathrm{h}$; and severe OSA: AHI > 30/h. PG was realized with ApneaLink (ResMed; San Diego, CA, USA) at home by trained physicians who were the members of the Study Board.

The SPT was done using Stallergenes Kit (Stallergenes; London, UK), and the negative control was $0.9 \%$ saline solution and the positive control was $1 \mathrm{mg} / \mathrm{mL}$ of histamine. Six respiratory allergens including Dermatophagoides pteronyssinus (Dp), Dermatophagoides farinae (Df), Blomia tropicalis (Blo), and hairs and epidermis of dogs, cats, and cockroaches were tested. The SPT was considered positive when the wheal size exceeded the negative control by $3 \mathrm{~mm}$.

Lung function testing (spirometry) was done by Koko (nSpire Health, Inc., Longmont, CO, USA). The reversibility of forced expiratory volume in $1 \mathrm{~s}\left(\mathrm{FEV}_{1}\right)$ was evaluated after using $200 \mu \mathrm{g}$ of salbutamol for $15 \mathrm{~min}$. The test was positive when there was an increase in $\mathrm{FEV}_{1} \geq 12 \%$ and $>200 \mathrm{~mL}$. Measuring exhaled NO concentration was done by Hypair FeNO+ Device (Medisoft; Sorinnes, Belgium) with expiratory air flow of 50, 100, 150, $350 \mathrm{~mL} / \mathrm{s}$. Fractional exhaled nitric oxide (FENO) levels were classified as recommended by the American Thoracic Society/European Respiratory Society (ATS/ERS) for children (<20 ppb: normal; 20-35 ppb: increased; and >35 ppb: highly increased). ${ }^{14}$ The level of alveolar concentration of exhaled $\mathrm{NO}\left(\mathrm{C}_{\mathrm{A}} \mathrm{NO}\right)$ $<5$ ppb was defined as normal. ${ }^{15}$

\section{Data collection}

All data on medical and family history, clinical characteristics, measures of spirometry, exhaled NO, SPT and PG 
parameters of the study subjects were collected for statistical analyses.

\section{Statistical analyses}

SPSS 22.0 software (IBM Corporation, Armonk, NY, USA) was used to analyze these collected data. Continuous variables were presented as mean \pm standard deviation (SD). Normal distribution was tested using the Skewness-Kurtosis technique. The pairwise comparison was performed using the Kruskal-Wallis test. The regression analysis was used to measure the correlation between AHI and continuous variables, with the correlation coefficient $R$ of Pearson for normal distribution variables and of Spearman for non-normal distribution variables. The Mann-Whitney $U$-test was used to evaluate the correlation between AHI and asthma severity.

\section{Results}

\section{Clinical and paraclinical characteristics of the study subjects}

Eighty-five children with asthma have been included in the present study. The mean age was $9.5 \pm 2.1$ years ( $6-12$ years) with $72.8 \%$ of male and $27.2 \%$ of female children (Table $1 \mathrm{~A}$ ). Approximately $78.8 \%$ of the study subjects had a history of atopic diseases, predominantly with allergic rhinitis (76.5\%); $7.1 \%$ of the study subjects were diagnosed with gastroesophageal reflux (GER) and 44.7\% with second hand smokers (Table 1A). Approximately $52.5 \%$ of the study subjects had mild asthma vs $18.8 \%$ intermittent asthma and $28.3 \%$ moderate asthma. Among them, only $29.4 \%$ subjects had been treated regularly and $18.8 \%$ had totally controlled asthma.

The majority of asthmatic children were allergic to house dust mites with $76.5 \%$ for Dp, $65.9 \%$ for Df, and $41.2 \%$ for Blomia (Table 1B). The mean levels of IgE and the percentage of eosinophil in the study subjects were higher than normal values. The mean $\mathrm{FEV}_{1}$ and peak expiratory flow (PEF) in the study subjects were mildly lower than normal value (Table 1B). Forty-four (51.4\%) asthmatic children were positive on the reversibility test. The nasal and alveolar concentrations of NO were higher than normal values (1501 $\pm 907 \mathrm{ppb}$ and $6.3 \pm 5.9 \mathrm{ppb}$, respectively; Table 1B).

There were $56(65.9 \%)$ asthmatic children who had OSA vs 29 (34.1\%) children with asthma who did not have OSA. Among the asthmatic children with OSA (56 patients), there were $31(55.4 \%)$ patients with mild OSA, 19 (33.9\%) with moderate OSA, and $6(10.7 \%)$ with severe OSA (AHI $\geq 10 / \mathrm{h})$. The average AHI index was $3.4 \pm 3.5 / \mathrm{h}(0-13 / \mathrm{h})$. The mean $\mathrm{SpO}_{2}$ was $84.6 \% \pm 20.8 \%$ and the nadir $\mathrm{SpO}_{2}$ was $79.6 \% \pm$ $8.2 \%$. The oxygen desaturation index (ODI) was $4.3 \pm 3.1 / \mathrm{h}$.
Table IA Clinical characteristics of the study subjects

\begin{tabular}{ll}
\hline Parameters (N = 85) & Mean \pm SD, N (\%) \\
\hline Age, years & $9.5 \pm 2.1$ \\
Male (female), \% & $72.8(28.2)$ \\
Height, cm & $134.5 \pm 12.5$ \\
Weight, kg & $31.9 \pm 8.2$ \\
BMI, kg/m² & $17.4 \pm 2.8$ \\
Atopic diseases, N (\%) & $67(78.8)$ \\
Eczema, \% & 21.2 \\
Allergic rhinitis, \% & 76.5 \\
Allergic conjunctivitis, \% & 35.3 \\
Urticaria, \% & 17.6 \\
Drug allergy, \% & 5.9 \\
Food allergy, \% & 16.5 \\
Familial history with allergy, N (\%) & $55(64.7)$ \\
GER, N (\%) & $6(7.1)$ \\
Second hand smoker, N (\%) & $38(44.7)$ \\
Asthma management, N (\%) & \\
$\quad$ Never treated & $26(30.6)$ \\
Occasionally treated & $34(40.0)$ \\
Correctly treated & $25(29.4)$ \\
Asthma severity, N (\%) &
\end{tabular}

Abbreviations: ACT, asthma control test; BMI, body mass index; GER, gastroesophageal reflux.

\section{Characteristics of the study subjects classified by OSA}

There was no significant difference in the anthropometric characteristics between asthmatic subjects with and without OSA (Table 2). There were also no significant differences in asthma treatment, asthma severity, and asthma control between the two groups $(P>0.05)$. The results showed that the prevalence of allergic rhinitis in asthma subjects with OSA was significantly higher than that in asthma subjects without OSA (69.6\% vs $46.2 \% ; P=0.006$; Table 2$)$. The levels of eosinophil, nasal FENO, $\mathrm{SpO}_{2}$, and nadir $\mathrm{SpO}_{2}$ were not significantly different between the two groups (Table 2). However, the levels of $\mathrm{FEV}_{1}$, bronchial FENO, and $\mathrm{C}_{\mathrm{A}} \mathrm{NO}$ in asthma subjects with OSA were significantly higher than that in subjects without OSA (Table 2).

\section{Characteristics of nocturnal and day-time symptoms}

The results showed that the percentages of asthmatic children with OSA who had snoring, disturbed sleep, and complaints 
Table IB Paraclinical characteristics of the study subjects

\begin{tabular}{|c|c|}
\hline Parameters $(\mathbf{N}=\mathbf{8 5})$ & Mean \pm SD, $\mathbf{N}(\%)$ \\
\hline \multicolumn{2}{|l|}{ SPT, N (\%) } \\
\hline Dp & $65 / 85(76.5)$ \\
\hline Df & $56 / 85(65.9)$ \\
\hline Blo & $35 / 85(41.2)$ \\
\hline Cockroaches & 16/85 (18.8) \\
\hline Dog hairs & I2/85 (14.1) \\
\hline Cat hairs & $24 / 85(28.2)$ \\
\hline \multicolumn{2}{|l|}{ Blood tests } \\
\hline Eosinophil, \% & $6.3 \pm 4.9$ \\
\hline CRP, mg/L & $3.1 \pm 4.7$ \\
\hline IgE, UI/L & $946.4 \pm 984.6$ \\
\hline \multicolumn{2}{|l|}{ Spirometry ${ }^{\mathrm{a}}, \%$} \\
\hline $\mathrm{FEV}_{1}$ & $89.4 \pm 15.9$ \\
\hline FVC & $95.5 \pm 15.2$ \\
\hline $\mathrm{FEV}_{1} / \mathrm{FVC}$ & $93.8 \pm 7.9$ \\
\hline PEF & $71.6 \pm 14.7$ \\
\hline \multicolumn{2}{|l|}{ Reversibility, N (\%) } \\
\hline Positive & $44(51.8)$ \\
\hline Negative & $4 I(48.2)$ \\
\hline \multicolumn{2}{|l|}{ Exhaled NO, ppb } \\
\hline Bronchial FENO & $19 \pm 14$ \\
\hline Nasal FENO & $|50| \pm 907$ \\
\hline $\mathrm{C}_{\mathrm{A}} \mathrm{NO}$ & $6.3 \pm 5.9$ \\
\hline \multicolumn{2}{|l|}{ Polygraphy } \\
\hline $\mathrm{AHI}(\min , \max )$ & $3.4 \pm 3.5(0-13)$ \\
\hline$\leq \mathrm{I} / \mathrm{h}$ (normal), $\mathrm{N}(\%)$ & $29(34.1)$ \\
\hline$>\mathrm{I} / \mathrm{h}(\mathrm{OSA}), \mathrm{N}(\%)$ & $56(65.9)$ \\
\hline $\mathrm{I}<\mathrm{AHI} \leq 5 / \mathrm{h}$ (mild), $\%$ & 55.4 \\
\hline $5<\mathrm{AHI} \leq \mathrm{I} 0 / \mathrm{h}$ (moderate) $\%$ & 33.9 \\
\hline$>10 / \mathrm{h}$ (severe), $\%$ & 10.7 \\
\hline $\mathrm{SpO}_{2}, \%$ & $84.6 \pm 20.8$ \\
\hline Nadir $\mathrm{SpO}_{2}, \%$ & $79.6 \pm 8.2$ \\
\hline
\end{tabular}

Notes: aPost-reversibility testing.

Abbreviations: $\mathrm{AHI}$, apnea-hypopnea index; Blo, Blomia tropicalis; CANO, alveolar concentration of nitric oxide; CRP, C reactive protein; Df, Dermatophagoides farinae; $\mathrm{Dp}$, Dermatophagoides pteronyssinus; FENO, fractional exhaled nitric oxide; FEV forced expiratory flow in I second; FVC, forced vital capacity; IgE, immunoglobulin E; max, maximum; min, minimum; NO, nitric oxide; OSA, obstructive sleep apnea; PEF, peak expiratory flow; SPT, skin prick test.

with nocturnal sweats were significantly higher than asthmatic children without OSA (48.2\% vs $17.2 \%, 71.4 \%$ vs $27.5 \%$, and $55.1 \%$ vs $31.0 \% ; P=0.002, P<0.001$, and $P=0.011$, respectively; Table 3 ). For daytime symptoms, the napping was presented only in asthmatic children with OSA while daytime sleepiness was presented predominantly in asthmatic children without OSA $(23.2 \%$ vs $0.0 \%$ and $37.9 \%$ vs $16.0 \% ; P=0.002$ and $P=0.012$, respectively; Table 3 ).

\section{Frequency of distribution of OSA and asthma severity}

The prevalence of mild OSA was significantly lower in children with moderate asthma in comparison with intermittent and mild asthma $(23.5 \%$ vs $63.6 \%$ and $71.4 \% ; P=0.016$
Table 2 Clinical and paraclinical characteristics of the study subjects classified by OSA

\begin{tabular}{|c|c|c|c|}
\hline Parameters & $\begin{array}{l}\text { Asthma + OSA } \\
(-), N=29\end{array}$ & $\begin{array}{l}\text { Asthma + OSA } \\
(+), N=56\end{array}$ & $P$ \\
\hline Age, years & $9.7 \pm 2.1$ & $9.4 \pm 2.1$ & 0.40 \\
\hline Male (female), ratio & $22 / 7(3.1)$ & $40 / 16(2.5)$ & 0.55 \\
\hline $\mathrm{BMI}, \mathrm{kg} / \mathrm{m}^{2}$ & $17.23 \pm 2.97$ & $|7.63 \pm 2.7|$ & 0.55 \\
\hline Allergic rhinitis, $N(\%)$ & $12(46.2)$ & $39(69.6)$ & 0.006 \\
\hline GER, $N(\%)$ & I (3.4) & $5(8.9)$ & 0.174 \\
\hline \multicolumn{4}{|c|}{ Asthma management, $\mathrm{N}(\%)$} \\
\hline Never treated & $8(27.6)$ & $18(32.1)$ & 0.332 \\
\hline Occasionally treated & $13(44.8)$ & $21(37.5)$ & 0.256 \\
\hline Correctly treated & $8(27.6)$ & $17(30.4)$ & 0.395 \\
\hline \multicolumn{4}{|l|}{ Asthma severity, $\mathrm{N}(\%)$} \\
\hline Intermittent & $5(17.2)$ & II (19.6) & 0.394 \\
\hline Mild & $17(58.6)$ & $30(50.8)$ & 0.328 \\
\hline Moderate & $7(24.2)$ & $15(30.4)$ & 0.395 \\
\hline \multicolumn{4}{|l|}{ Asthma control, $\mathrm{N}(\%)$} \\
\hline Controlled & $6(20.7)$ & $10(17.9)$ & 0.375 \\
\hline Partial controlled & $9(31.0)$ & $16(28.6)$ & 0.406 \\
\hline Uncontrolled & $14(48.3)$ & $30(53.5)$ & 0.321 \\
\hline ACT, score & $19.9 \pm 4.1$ & $20.5 \pm 3.6$ & 0.572 \\
\hline Eosinophil, \% & $7.2 \pm 6.2$ & $5.9 \pm 4.2$ & 0.24 \\
\hline $\mathrm{FEV}_{1}, \%$ & $94.8 \pm 15.2$ & $86.5 \pm 15.6$ & 0.022 \\
\hline \multicolumn{4}{|l|}{ Exhaled NO, ppb } \\
\hline Bronchial FENO & $14.3 \pm 11.9$ & $21.0 \pm 12.9$ & 0.034 \\
\hline Nasal FENO & $1489 \pm 833$ & $150 \mid \pm 954$ & 0.954 \\
\hline $\mathrm{C}_{\mathrm{A}} \mathrm{NO}$ & $3.2 \pm 2.1$ & $6.5 \pm 7.3$ & 0.028 \\
\hline \multicolumn{4}{|l|}{ Polygraphy } \\
\hline $\mathrm{AHI}(\min , \max )$ & - & $3.4 \pm 3.5(0-13)$ & - \\
\hline $\mathrm{SpO}_{2}$ & $92 \pm 2$ & $92 \pm 4$ & 0.791 \\
\hline Nadir $\mathrm{SpO}_{2}, \%$ & $86 \pm 8$ & $82 \pm 7$ & 0.405 \\
\hline ODI, /h & $1.6 \pm 2.2$ & $2.3 \pm 2.4$ & 0.315 \\
\hline
\end{tabular}

Abbreviations: $\mathrm{ACT}$, asthma control test; $\mathrm{AHI}$, apnea-hypopnea index; $\mathrm{BMI}$, body mass index; CANO, alveolar concentration of nitric oxide; FENO, fractional exhaled nitric oxide; FEV , forced expiratory flow in I second; FVC, forced vital capacity; GER, gastroesophageal reflux; max, maximum; min, minimum; NO, nitric oxide; ODI, oxygen desaturation index; OSA, obstructive sleep apnea; PEF, peak expiratory flow.

Table 3 Characteristics of nocturnal and day-time symptoms

\begin{tabular}{|c|c|c|c|}
\hline Characteristics & $\begin{array}{l}\text { Asthma-OSA } \\
(-), N=29\end{array}$ & $\begin{array}{l}\text { Asthma-OSA } \\
(+), N=56\end{array}$ & $\mathbf{P}$ \\
\hline \multicolumn{4}{|c|}{ Nocturnal symptoms, N (\%) } \\
\hline Snoring & $5(17.2)$ & $27(48.2)$ & 0.002 \\
\hline Difficulty sleeping & $5(17.2)$ & II (19.6) & 0.397 \\
\hline Dyspnea during sleep & $7(24.1)$ & $32(57.1)$ & 0.002 \\
\hline Witness of apnea & $0(0)$ & I (I.7) & 0.234 \\
\hline Sleep disturbance & $8(27.5)$ & $40(71.4)$ & $<0.001$ \\
\hline Frequently awake & $12(41.3)$ & $16(28.5)$ & 0.116 \\
\hline Nocturnal sweats & $9(3 \mid .0)$ & $32(55.1)$ & 0.011 \\
\hline Enuresis & $10(34.4)$ & $6(10.7)$ & 0.003 \\
\hline \multicolumn{4}{|c|}{ Daytime symptoms, N (\%) } \\
\hline Abnormal behavior & $9(31.0)$ & $13(23.2)$ & 0.217 \\
\hline Irritability & $8(27.5)$ & $21(37.5)$ & 0.180 \\
\hline Reduced awareness & $0(0)$ & $2(3.5)$ & 0.151 \\
\hline Daytime sleepiness & II (37.9) & $9(16.0)$ & 0.012 \\
\hline Doze & $0(0)$ & $13(23.2)$ & 0.002 \\
\hline
\end{tabular}

Abbreviation: OSA, obstructive sleep apnea. 
and $P=0.0008$, respectively; Figure 1A). There were no significant differences in the prevalence of moderate OSA in children with intermittent, mild, and moderate asthma (36.4\% vs $25.0 \%$ vs $47.1 \% ; P=0.238, P=0.288$, and $P=0.064$, respectively). The prevalence of severe OSA in children with moderate asthma was significantly higher than in those with intermittent and mild asthma $(29.4 \%$ vs $0.0 \%$ and $3.6 \%$; $P=0.023$ and $P=0.006$, respectively; Figure 1A).
Similarly, the prevalence of mild asthma in children with severe OSA was significantly lower than that in asthmatic children without OSA and with mild OSA $(16.7 \%$ vs $58.6 \%$ and $64.5 \% ; P=0.030$ and $P=0.015$, respectively; Figure 1B). The prevalence of moderate asthma in children with severe OSA was significantly higher than that in asthma children without and with mild to moderate OSA $(83.3 \%$ vs $24.2 \%$, $12.9 \%$, and $42.1 \% ; P=0.020, P=0.0002$, and $P=0.039$,

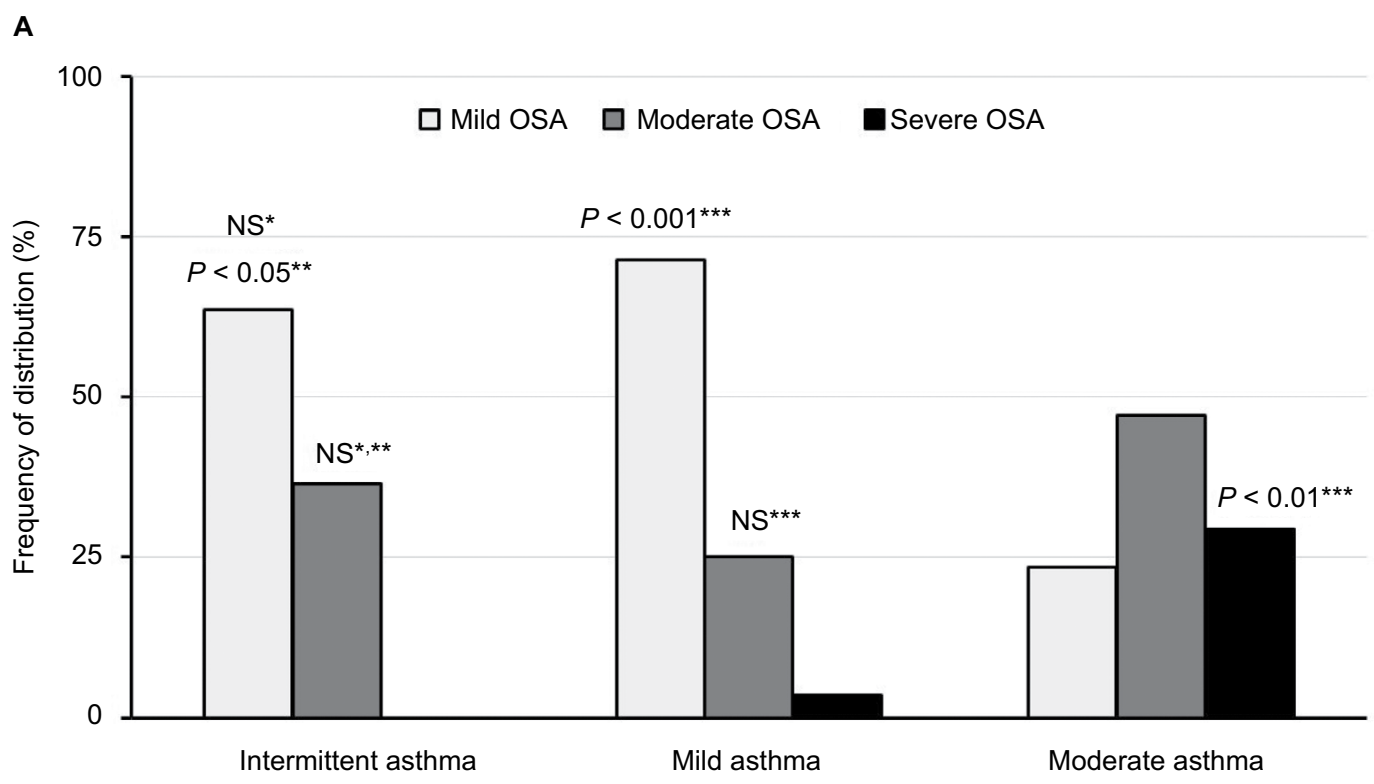

Distribution of OSA severity depending on asthma severity

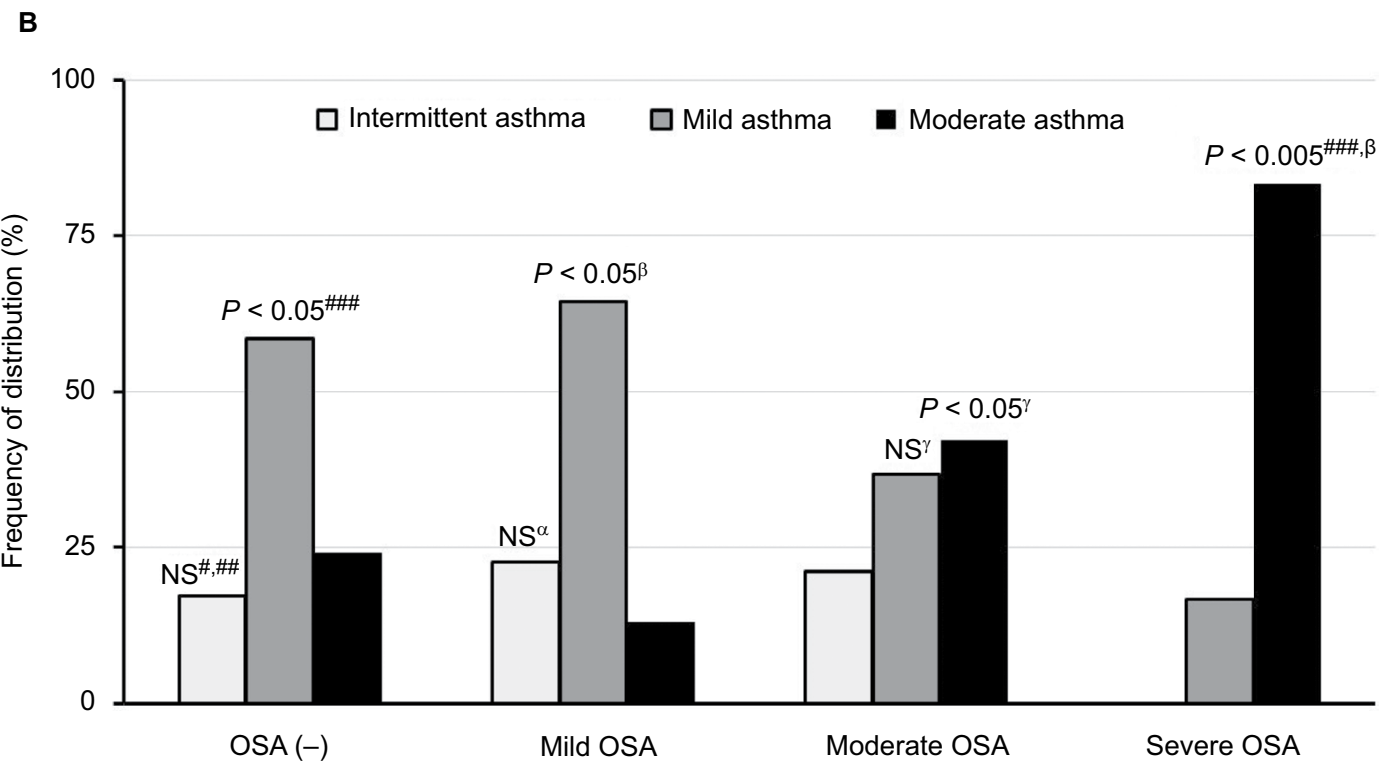

Distribution of asthma severity depending on OSA severity

Figure I Frequency of distribution of OSA and asthma severity.

Notes: (A) Distribution of OSA severity depending on asthma severity and (B) distribution of asthma severity depending on OSA severity. *intermittent asthma vs mild asthma; **intermittent asthma vs moderate asthma; ***mild asthma vs moderate asthma; ${ }^{*}$ OSA (-) vs mild asthma; ${ }^{*}$ OSA (-) vs moderate OSA; ${ }^{*}$ OSA (-) vs severe OSA; ${ }^{\alpha}$ mild OSA vs moderate OSA; ${ }^{\beta}$ mild OSA vs severe OSA; ${ }^{\gamma}$ moderate OSA vs severe OSA.

Abbreviations: OSA, obstructive sleep apnea; OSA (-), subjects without OSA; NS, not significant. 
respectively; Figure 1B). However, there were no significant differences in the prevalence of intermittent asthma in children without OSA and with mild, moderate, and severe OSA $(17.2 \%, 22.6 \%, 21.1 \%$, and $0.0 \% ; P=0.302, P=0.370$, $P=0.135, P=0.449, P=0.09$, and $P=0.110$, respectively).

\section{Relative measure (odds ratio, $O R$ ) of OSA risk in the study subjects}

The presence of allergic rhinitis and snoring was associated significantly with high probability for the presence of OSA $(\mathrm{OR}=6.8$, CI 95\%: 2.2-20.7, $P=0.001 ; \mathrm{OR}=4.9,95 \%$ CI: $1.8-13.3, P=0.002$, respectively; Table 4; Figure 2). However, the presence of disturbed sleep, nocturnal sweats, and $\mathrm{FEV}_{1}<80 \%$ of predicted value was not associated with a significant presence of OSA in subjects with asthma (Table 4 and Figure 2). The presence of increased exhaled NO (bron-

Table 4 Measure of odds ratio for OSA in the study subjects with asthma

\begin{tabular}{llll}
\hline Parameters & $\begin{array}{l}\text { Odds } \\
\text { ratio }\end{array}$ & $\begin{array}{l}\text { Cl 95\% Odds } \\
\text { ratio }\end{array}$ & $\boldsymbol{P}$ \\
\hline Allergic rhinitis & 6.8 & $2.2-20.7$ & 0.001 \\
Snoring & 4.9 & $1.8-13.3$ & 0.002 \\
Disturbed sleep & 2.0 & $0.8-5.4$ & 0.156 \\
Dyspnea during sleep & 4.2 & $1.5-11.4$ & 0.005 \\
Nocturnal sweats & 1.1 & $0.4-2.7$ & 0.862 \\
FEV $1<80 \%$ & 3.0 & $0.9-9.8$ & 0.067 \\
Bronchial FENO $>20 \mathrm{ppb}$ & 0.9 & $0.4-2.3$ & 0.840 \\
$\mathrm{C}_{\mathrm{A}}$ NO $>5$ ppb & 0.9 & $0.4-2.3$ & 0.862 \\
\hline
\end{tabular}

Abbreviations: $C_{A} N O$, alveolar concentration of nitric oxide; FENO, fractional exhaled nitric oxide; $\mathrm{FEV}_{1}$, forced expiratory volume in I s; NO, nitric oxide; OSA, obstructive sleep apnea; ppb, part per billion. chial and alveolar exhaled NO) was not a predictive factor for the presence of OSA in the study subjects.

\section{Discussion}

The results of the present study showed that 1) the prevalence of OSA in children with asthma was predominantly in moderate asthma; 2) the prevalence of allergic rhinitis and sleep-related disorders in asthma subjects with OSA was significantly higher than that in subjects without OSA; 3) the level of exhaled $\mathrm{NO}$ (FENO and $\mathrm{C}_{\mathrm{A}} \mathrm{NO}$ ) in asthma subjects with OSA was significantly higher than subjects without OSA; and 4) the presence of allergic rhinitis, dyspnea, and snoring during sleep in asthma subjects was significantly associated with a higher probability of the presence of OSA.

In the present study, $65.9 \%$ of the asthmatic patients having OSA were diagnosed by PG (AHI $\geq 1 / \mathrm{h}$; Table $1 \mathrm{~B})$. However, if study subjects with mild OSA should be excluded from the analysis or the cutoff of AHI $>5$ for diagnosis of OSA, the percentage of children with asthma having OSA will be significantly lower (36.5\%; data not shown). Especially, the prevalence of severe OSA in subjects with moderate asthma was significantly higher than intermittent and mild asthma subjects and inversely the percentage of patients with moderate asthma was significantly higher in severe OSA (Tables $1 \mathrm{~A}$ and $1 \mathrm{~B}$ ). In addition, AHI was significantly higher in patients with moderate asthma and in uncontrolled asthma (data not shown). However, there were no significant differences between asthma subjects with OSA and without OSA for the distribution frequency of asthma

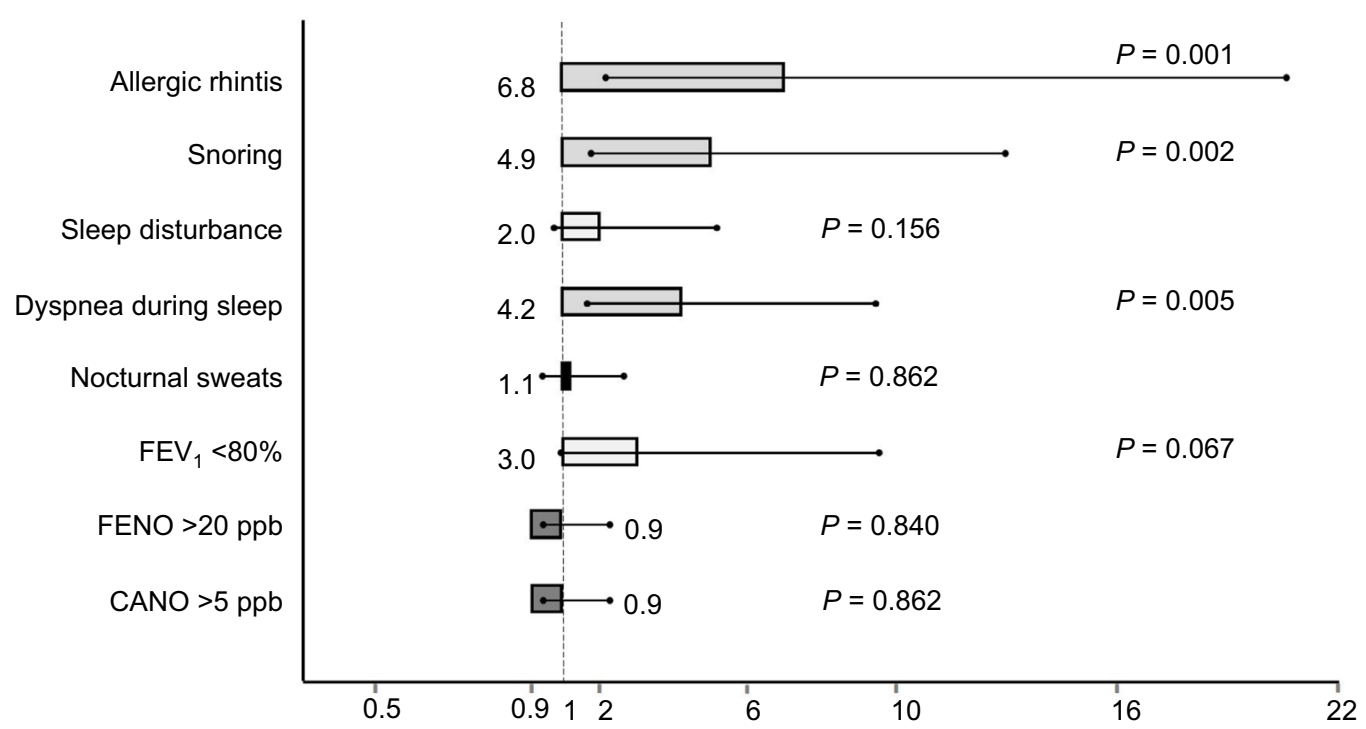

Figure 2 Distribution of odds ratio for OSA in the study subjects with asthma.

Abbreviations: $\mathrm{C}_{\mathrm{A}} \mathrm{NO}$, alveolar concentration of nitric oxide; FENO, fractional exhaled nitric oxide; FEV , forced expiratory volume in I s; NO, nitric oxide; Ppb, part per billion; OSA, obstructive sleep apnea. 
severity, treatment adherence, and asthma control (Table 2). Previous studies also demonstrated the correlation between asthma severity and AHI. ${ }^{7,16}$ In adults, Julien et al $^{16}$ showed that the prevalence of OSA, diagnosed by AHI $\geq 15 / \mathrm{h}$, was $88 \%$ in the severe asthma group and $58 \%$ in the moderate asthma group. ${ }^{16}$ In children, based on the result of a recent systematic review, Sánchez et $\mathrm{al}^{7}$ concluded that children with asthma were more likely to develop habitual snoring and OSA, and children with sleep-disordered breathing (SDB) were more likely to develop asthma. Moreover, the authors found out that asthma was associated with more severe OSA, and the presence of SDB was associated with severe asthma.

The present study showed that $78.8 \%$ of the study subjects had an atopic disease with $76.5 \%$ of allergic rhinitis, diagnosed by clinical symptoms and nasal FENO measurement (Tables 1A and 1B). The high prevalence of allergic rhinitis in asthma subjects in the present study was similar to another previous study. ${ }^{17}$ Braido et al ${ }^{18}$ found that approximately $80 \%$ of patients with asthma had allergic rhinitis as a comorbidity and increased risk of OSA. As with our previous study, ${ }^{17}$ in the present study, there were $>80 \%$ of asthma patients with allergic rhinitis having nasal congestion. It has been suggested that nasal congestion, a prominent and bothersome symptom of allergic rhinitis, is linked to SDB, including snoring and sleep apnea. ${ }^{19,20}$ The role of nasal congestion in increasing the AHI has been confirmed by previous studies in sleep-related problems with the nasal occlusion model. ${ }^{21,22}$ However, until now, the exact mechanism for the link between allergic rhinitis and OSA has not been clearly identified.

The results of our study show that the percentage of asthma subjects with OSA having snoring, disturbed sleep, apnea during sleep, nocturnal sweats, and day-time sleepiness was significantly higher than that in asthma subjects without OSA (Table 3). These symptoms were discovered by parents at night during sleep and at schools during class. The sleepiness during class time might reflect significantly on the day-time consequence of bad sleep quality. In addition, among these symptoms, there was only the snoring and dyspnea during sleep and a high probability for the presence of OSA in asthma subjects (Table 4). This result might be very interesting in regard to the use of snoring and dyspnea during sleep as suggestive symptoms of OSA in patients with asthma. Inversely, the results of previous studies showed that subjects with habitual snoring and OSA had a statistically significant predictor of asthma. ${ }^{23-25}$ However, the bidirectional correlation between asthma and OSA is still controversial. ${ }^{26}$ OSA may induce asthma exacerbation via different mechanisms such as by altering oropharyngeal reflex or increasing cholinergic tone. ${ }^{27}$ However, asthma may induce disrupted sleep and increased AHI in snorers. ${ }^{28}$ In addition, in asthmatic children with OSA, uncontrolled asthma might accentuate upper and lower airway inflammation via the intermittent nocturnal hypoxemia. ${ }^{28,29}$ The present study showed that enuresis was not a specific symptom of OSA in children with asthma because it was present predominantly in children without OSA (Table 3).

The present study also showed that asthma patients with OSA had some paraclinical parameters significantly different from asthma patients without OSA (Table 1B). Asthma subjects with OSA had a lower $\mathrm{FEV}_{1}$ and higher exhaled NO levels (bronchial FENO and $\mathrm{C}_{\mathrm{A}} \mathrm{NO}$ ) than asthma subjects without OSA. The low $\mathrm{FEV}_{1}$ in asthma subjects (moderate asthma) with OSA was similar to the high distribution prevalence of moderate to severe OSA in these patients (Figure 1A and B). This result suggests that there was a link between airway obstruction in asthma and OSA severity. In the present study, the spirometry parameters had been used mainly to evaluate the severity of airflow limitation and its reversibility as recommended by GINA, and due to the study population was children, the other lung testing such as diffusing capacity of lung for carbon monoxide (DLCO) had not been done for additional parameter analysis.

The results of our previous study on subjects with OSA and without asthma demonstrated that the level of $\mathrm{C}_{\mathrm{A}} \mathrm{NO}$ was significantly increased at wake up, suggesting that the measurement of $\mathrm{C}_{\mathrm{A}} \mathrm{NO}$ at wake up was useful to predict the risk of OSA in subjects with suggestive symptoms. ${ }^{15}$ Therefore, $\mathrm{C}_{\mathrm{A}} \mathrm{NO}$ may be used as a surrogate marker for subjects with OSA without other airway diseases. However, the role of $\mathrm{C}_{\mathrm{A}} \mathrm{NO}$ in asthma subjects with OSA has not been demonstrated. In the present study, although the level of $\mathrm{C}_{\mathrm{A}} \mathrm{NO}$ was significantly higher in asthma subjects with OSA than that in asthma subjects without OSA, there was no significant link between increased $\mathrm{C}_{\mathrm{A}} \mathrm{NO}$ and OSA risk (Table 4 and Figure 2). Hence, we suggest that the high level of $\mathrm{C}_{\mathrm{A}} \mathrm{NO}$ in asthma patients with OSA might be due to airway inflammation rather than oxidative stress.

The results of measuring the OR of significant clinical and functional features in asthma subjects with OSA in the present study showed that the presence of allergic rhinitis and snoring was associated with a higher probability for the presence of OSA (Table 4 and Figure 2). This result suggests that the presence of allergic rhinitis, a common comorbidity in asthma patients, is a risk for OSA, especially when it is associated with snoring at night. The presence of allergic rhinitis and snoring in asthma subjects might be considered as 
a relevant marker of OSA and also a main criterion for investigating sleep-disorder breathing with PG or polysomnography. Interestingly, the coexistence of asthma and OSA might be a specific clinical phenotype for the management and the control of asthma in children. More studies are necessary to study the role of treatment option for asthmatic children with OSA; it should be based on the presence or absence of allergic rhinitis as a treatable comorbidity and the efficacy of some recommended drugs such as leukotriene antagonists.

\section{Conclusion}

OSA is a common comorbidity in children with asthma. It was dominant in subjects with moderate and uncontrolled asthma. The presence of allergic rhinitis, snoring, and dyspnea during sleep in asthmatic children is associated with a higher risk of OSA. Hence, PG or polysomnography should be performed on asthmatic children with suggestive symptoms of OSA.

\section{Disclosure}

The authors report no conflicts of interest in this work.

\section{References}

1. Sateia MJ. International classification of sleep disorders-third edition: highlights and modifications. Chest. 2014;146(5):1387-1394.

2. Franklin KA, Lindberg E. Obstructive sleep apnea is a common disorder in the population-a review on the epidemiology of sleep apnea. JThorac Dis. 2015;7(8):1311-1322.

3. DelRosso LM. Epidemiology and diagnosis of pediatric obstructive sleep apnea. Curr Probl Pediatr Adolesc Health Care. 2016;46(1):2-6.

4. Tan HL, Gozal D, Kheirandish-Gozal L. Obstructive sleep apnea in children: a critical update. Nat Sci Sleep. 2013;5:109-123.

5. Kaditis AG, Kalampouka E, Hatzinikolaou S, et al. Associations of tonsillar hypertrophy and snoring with history of wheezing in childhood. Pediatr Pulmonol. 2010;45(3):275-280.

6. Teodorescu M, Consens FB, Bria WF, et al. Predictors of habitual snoring and obstructive sleep apnea risk in patients with asthma. Chest. 2009;135(5):1125-1132.

7. Sánchez T, Castro-Rodríguez JA, Brockmann PE. Sleep-disordered breathing in children with asthma: a systematic review on the impact of treatment. J Asthma Allergy. 2016;9:83-91.

8. Hiren M, Arens R. Diagnostic issues in pediatric obstructive sleep apnea. Proc Am Thorac Soc. 2008;5(2):263-273.

9. James C, Peter JC, Koltai J. Obstructive sleep apnea in children. Am Fam Physician. 2004;69(5):1147-1155.

10. Desager KN, Nelen V, Weyler JJJ, De Backer WA. Sleep disturbance and daytime symptoms in wheezing school-aged children. J Sleep Res. 2005;14(1):77-82.
11. Salles C, Terse-Ramos R, Souza-Machado A, Cruz ÁA. Obstructive sleep apnea and asthma. J Bras Pneumol. 2013;39(5):604-612.

12. GINASTHMA. Global Initiative for Asthma. 2015. Available from: http://ginasthma.org/wp-content/uploads/2016/01/GINA_ Report_2015_Aug11-1.pdf. Accessed November 12, 2015.

13. Dehlink E, Tan H-L. Update on paediatric obstructive sleep apnoea. J Thorac Dis. 2016;8(2):224-235.

14. Dweik RA, Boggs PB, Erzurum SC, et al; American Thoracic Society Committee on Interpretation of Exhaled Nitric Oxide Levels (FENO) for Clinical Applications. An official ATS clinical practice guideline: interpretation of exhaled nitric oxide levels (FENO) for clinical applications. Am J Respir Crit Care Med. 2011;184(5):602-615.

15. Duong-Quy S, Hua-Huy T, Tran-Mai-Thi HT, Le-Dong NN, Craig TJ, Dinh-Xuan AT. Study of exhaled nitric oxide in subjects with suspected obstructive sleep apnea: a pilot study in Vietnam. Pulm Med. 2016;2016:3050918.

16. Julien JY, Martin JG, Ernst P, et al. Prevalence of obstructive sleep apnea-hypopnea in severe versus moderate asthma. J Allergy Clin Immunol. 2009;124(2):371-376.

17. Duong-Quy S, Vu-Minh T, Hua-Huy T, et al. Study of nasal exhaled nitric oxide levels in diagnosis of allergic rhinitis in subjects with and without asthma. J Asthma Allergy. 2017;10:75-82.

18. Braido F, Baiardini I, Lacedonia D, et al; Italian Society of Respiratory Medicine (SIMeR). Sleep apnea risk in subjects with asthma with or without comorbid rhinitis. Respir Care. 2014;59(12):1851-1856.

19. Léger D, Annesi-Maesano I, Carat F, et al. Allergic rhinitis and its consequences on quality of sleep: an unexplored area. Arch Intern Med. 2006;166(16):1744-1748.

20. Ng DK, Chan CH, Kwok KL, Cheung JM. Allergic rhinitis as a risk factor for habitual snoring in children. Chest. 2005;127(6):2285-2286; author reply 2286 .

21. Suratt PM, Turner BL, Wilhoit SC. Effect of intranasalobstruction on breathing during sleep. Chest. 1986;90(3):324-329.

22. Lavie P, Fischel N, Zomer J, Eliaschar I. The effects of partial and complete mechanical occlusion of the nasal passages on sleep structure and breathing in sleep. Acta Otolaryngol. 1983;95(1-2):161-166.

23. Lu LR, Peat JK, Sullivan CE. Snoring in preschool children: prevalence and association with nocturnal cough and asthma. Chest. 2003;124(2):587-593.

24. Li L, Xu Z, Jin X, et al. Sleep-disordered breathing and asthma: evidence from a large multi-centric epidemiological study in China. Respir Res. 2015;16:56.

25. Ross KR, Storfer-Isser A, Hart MA, et al. Sleep-disordered breathing is associated with asthma severity in children. $J$ Pediatr. 2012;160(5):736-742.

26. Abdul Razak MR, Chirakalwasan N. Obstructive sleep apnea and asthma. Asian Pac J Allergy Immunol. 2016;34:265-271.

27. Chng SY, Goh DYT, Wang XS, Tan TN, Ong NBH. Snoring and atopic disease: a strong association. Pediatr Pulmonol. 2004;38(3):210-216.

28. Gozal D, Sans Capdevila O, Kheirandish-Gozal L. Metabolic alterations and systemic inflammation in obstructive sleep apnea among nonobese and obese prepubertal children. Am J Respir Crit Care Med. 2008;177(10):1142-1149.

29. Malakasioti G, Gourgoulianis K, Chrousos G, Kaditis A. Interactions of obstructive sleep-disordered breathing with recurrent wheezing or asthma and their effects on sleep quality. Pediatr Pulmonol. 2011;46(11):1047-1054.
Journal of Asthma and Allergy

\section{Publish your work in this journal}

The Journal of Asthma and Allergy is an international, peer-reviewed open access journal publishing original research, reports, editorials and commentaries on the following topics: Asthma; Pulmonary physiology; Asthma related clinical health; Clinical immunology and the immunological basis of disease; Pharmacological interventions and

\section{Dovepress}

new therapies. This journal is included in PubMed. The manuscript management system is completely online and includes a very quick and fair peer-review system, which is all easy to use. Visit http://www. dovepress.com/testimonials.php to read real quotes from published authors. 